\title{
Grafos e máquinas de estados finitos: uma experiência interdisciplinar com estudantes da educação profissional
}

Lauro Chagas e Sá

lauro.sa@ifes.edu.br 0000-0003-1820-4856

Instituto Federal de Educação, Ciência e Tecnologia do Espírito Santo - campus Viana; Espírito Santo, Brasil.

\section{Fabrício Bortolini de Sá} fabricio.sa@ifes.edu.br 0000-0002-3403-4829

Instituto Federal de Educação, Ciência Tecnologia do Espírito Santo - campus Linhares; Espírito Santo, Brasil.

Sandra Aparecida Fraga da Silva sfraga@ifes.edu.br

0000-0002-0902-627X

Educação, Ciência Tecnologia do Espirito Santo - campus Vitória; Espírito Santo, Brasil.

\section{RESUMO}

Apresentamos um recorte de pesquisa de mestrado que investigou aprendizagens discentes durante construção e utilização de uma maquete eletrônica para ensino da Teoria de Grafos. Identificamos aprendizagens dos alunos-pesquisadores da educação profissional no movimento da pesquisa-ação que oportunizou a criação do recurso. Partimos das perguntas: como se deu a interação ciência e tecnologia no projeto de feira de matemática? Que conteúdos foram mobilizados durante o movimento da pesquisa-ação? Como isso aconteceu? Buscando respostas, analisamos conversas de Whatsapp e respostas a um formulário e a um questionário, nossos instrumentos para produção de dados. Ao final, destacamos a relação entre o grafo, elemento matemático, e sua utilização para produção da maquete eletrônica, por meio da utilização de máquinas de estados finitos. Assim, ao retomarmos os conteúdos matemáticos e do núcleo profissional, acreditamos ter desenvolvido um trabalho interdisciplinar, reconstituindo a totalidade do conhecimento pela relação entre distintos conceitos abordados.
\end{abstract}

PALAVRAS-CHAVE: Interdisciplinaridade, Feira de Matemática, Educação Profissional, Educação Matemática. 


\section{INTRODUÇÃO}

Este texto apresenta recorte de pesquisa de mestrado (SÁ, 2016), de natureza qualitativa, que investigou aprendizagens discentes durante construção e utilização de uma maquete eletrônica para ensino da Teoria de Grafos. Adotamos como formato metodológico a pesquisa-ação, considerando a participação de alunos e professores do curso técnico em Automação Industrial do Instituto Federal do Espírito Santo, campus Linhares, na construção da maquete eletrônica que proporcionou a abordagem inicial de grafos com estudantes de ensino médio da rede estadual de educação.

Apesar do foco inicial da pesquisa estar na utilização da maquete eletrônica por alunos de ensino médio da rede estadual de educação, julgamos importante também identificar aprendizagens dos alunos-pesquisadores da educação profissional, no movimento da pesquisa-ação, que oportunizou a criação do recurso e sua apresentação em uma feira de matemática. Este será, portanto, nosso recorte para esta publicação. Nas páginas a seguir, responderemos às seguintes perguntas: como se deu a interação ciência e tecnologia no projeto de feira de matemática? Quais conteúdos foram mobilizados durante o movimento da pesquisa-ação e como aconteceu essa mobilização?

\section{PRESSUPOSTOS TEÓRICOS}

Com base no que Paulo Freire escreve sobre a educação, é possível afirmar que, para ele, a educação profissional deve ser entendida como um processo de formação humana: "a formação técnico-científica de que precisamos é muito mais do que puro treinamento ou adestramento para uso de procedimentos tecnológicos" (FREIRE, 2000, p. $101^{1}$ apud MANFREDI, 2010, p. 140). Nesse sentido, a formação técnica deve compreender conhecimentos técnicos, científicos, em sua historicidade e com a função social e política.

Considerando as múltiplas contribuições das Feiras de Ciência e Matemática para alunos, comunidade escolar e sociedade, concordamos com Moura (1995, p. 7) que as Feiras de Ciências são vistas como "espaço de interação com as áreas de ciência e tecnologia; oportunidade de ensino e de aprendizagem para professores e alunos; e de desenvolvimento do aluno em suas dimensões sociais, afetivas, cognitivas e psicológicas". A relação entre ciência e tecnologia, marcante no ensino de ciências naturais, também pode ser potencializada na área de matemática, a partir da realização de feiras. Silva e Tomelin $(2008$, p. 17) reforçam esta ideia quando afirmam que "as feiras ajudam a ampliar os conhecimentos em Matemática e em outras áreas".

Sobre o processo de investigação no ensino de Matemática, Skovsmose (2000) destaca que o paradigma do exercício, marcante na cultura escolar, pode ser contraposto a uma abordagem de investigação. Segundo o pesquisador, nesse modo de se trabalhar, cria-se um cenário que convida os alunos a formularem questões e procurarem explicações. Assim, nas palavras de Skovsmose (2000, p. 81), "quando os alunos assumem o processo de exploração e explicação, o cenário para investigação passa a constituir um novo ambiente de aprendizagem". $O$ autor aponta que práticas de sala de aula planejadas num cenário para investigação diferem fortemente daquelas baseadas em exercícios. A distinção entre essas práticas deriva das "referências" que levam os estudantes a produzirem 
significados para os conceitos e atividades matemáticas. Diferentes tipos de referência são possíveis, uma vez que exercícios e atividades investigativas podem se referir à matemática e somente a ela, a uma semi realidade ou a situações da vida real (SKOVSMOSE, 2000). Combinando a distinção entre os três tipos de referência e os dois paradigmas de práticas de sala de aula apresentados em Skovsmose (2000), obtém-se uma matriz com seis tipos diferentes de ambientes de aprendizagem:

Quadro 1 - Ambientes de aprendizagem

\begin{tabular}{c|c|c} 
Referências à & Paradigma do exercício & Cenário de investigação \\
\hline matemática pura & $\begin{array}{c}\text { Ambiente (1), dominado por } \\
\text { exercícios da "matemática pura", } \\
\text { como cálculos literais e operações } \\
\text { aritméticas sem contexto. }\end{array}$ & $\begin{array}{c}\text { Ambiente (2), caracterizado como } \\
\text { um ambiente que envolve } \\
\text { números e figuras geométricas. }\end{array}$ \\
\hdashline $\begin{array}{c}\text { Refências à semi } \\
\text { realidade }\end{array}$ & $\begin{array}{c}\text { Ambiente (3), constituído por } \\
\text { exercícios com referências a semi } \\
\text { realidade². }\end{array}$ & $\begin{array}{c}\text { Ambiente (4), onde a semi } \\
\text { realidade é um convite para que } \\
\text { os alunos façam explorações e } \\
\text { explicações. }\end{array}$ \\
\hdashline Referências à \\
realidade & $\begin{array}{c}\text { Ambiente (5), que contém exercícios } \\
\text { baseados na vida real, como } \\
\text { questões construídas a partir de } \\
\text { matérias de jornal. Ainda assim, as } \\
\text { atividades estão estabelecidas no } \\
\text { paradigma do exercício. } \\
\text { Fonte: Adaptado de Skovsmose }\end{array}$ & $\begin{array}{c}\text { Ambiente (6), que se difere do (5) } \\
\text { pelo convite à investigação. Pode } \\
\text { ser construído em sala de aula } \\
\text { com a realização de projetos. }\end{array}$ \\
\hline (200).
\end{tabular}

Apesar de ser uma simplificação, o Quadro 1 nos permite refletir sobre como os ambientes influenciam na construção do conhecimento matemático. Ainda sobre a matriz, Skovsmose (2000, p. 79) destaca que "a linha vertical que separa o paradigma do exercício dos cenários para investigação é, por certo, uma linha muito 'espessa', simbolizando um terreno imenso de possibilidades". Assim, percebemos que projetos de feira de matemática com alunos do ensino médio/educação profissional apresentam aspectos do ambiente de aprendizagem (6), constituído por uma abordagem investigativa com referência à realidade. Em especial, quando eles são abordados na proposta de pesquisa-ação, conforme descrevemos a seguir.

\section{METODOLOGIA}

Considerando reflexões suscitadas a partir da relação entre teoria e prática, percebemos que a pesquisa-ação, de natureza qualitativa, emerge como uma possibilidade de abordagem investigativa na área de ensino de Matemática, com muitas aproximações neste trabalho, que ocorreu entre dezembro de 2014 e dezembro de 2015. A pesquisa-ação, segundo Fiorentini e Lorenzato (2009), é um processo investigativo de intervenção em que caminham juntas a prática investigativa, a prática reflexiva e a prática educativa. Para esses autores, na pesquisa-ação, "o observador se introduz no ambiente a ser estudado não só para observá-lo e compreendê-lo, mas sobretudo para mudá-lo em direção que permita a melhoria das práticas e maior liberdade de ação e de aprendizagem dos 
participantes" (p. 112). Nessa mesma perspectiva, Thiollent (2011, p. 85) destaca que a pesquisa-ação "promove a participação dos usuários do sistema escolar na busca de soluções aos seus problemas". Em relação às etapas para realizar uma pesquisa-ação, cabe apontar que o método é o da espiral auto-reflexiva (FIORENTINI \& LORENZATO, 2009), com suas fases de planejamento, de ação, de observação e de reflexão, depois de um novo planejamento da experiência em curso.

A parte inicial da pesquisa, relativa à construção da maquete, foi desenvolvida com alunos do curso técnico em Automação Industrial Integrado ao Ensino Médio do Instituto Federal de Educação, Ciência e Tecnologia do Espírito Santo (Ifes) campus Linhares. Nesta pesquisa, esses alunos-pesquisadores receberam os pseudônimos de Sabrina, Elis, Thiago e João. Dessa forma, a composição do grupo foi de quatro alunos do ensino médio integrado ao técnico em Automação Industrial do Ifes/Linhares, um professor com formação em engenharia e um professor com formação em matemática, sendo este último o pesquisador de mestrado. Essa composição manteve-se até dezembro de 2015 , quando os alunos ensino médio integrado concluíram o curso e se desligaram da instituição.

As etapas da pesquisa-ação com os alunos do ensino médio compreenderam fase exploratória, realização de seminários internos (com outros alunos da instituição), registros em atas, construção da maquete eletrônica, apresentação do projeto em feiras e validação da proposta educativa em uma escola da rede pública. Neste trabalho, exploramos a relação entre ciência e tecnologia, identificadas a partir das conversas de $W_{\text {hatsapp }}^{3}$, de um formulário eletrônico e de um questionário, que se constituíram como instrumentos para produção de dados durante a pesquisa-ação.

\section{REFLEXÕES SOBRE A PRÁTICA}

Durante o período exploratório - de definição do tema -, o grupo negociou uma abordagem metodológica, que poderia ser com aplicações da Teoria de Grafos, sua história ou jogos associados ao conteúdo, conforme trecho de conversa Whatsapp apresentado abaixo:

12/01/2015, 15h36 - Pesquisador: Boa tarde, pessoal! Como tem passado de férias? Estou escrevendo os projetos dos demais grupos. Se quiserem participar da Semana da Matemática, vocês precisam definir um tema até o fim do mês, ok? Abraços

12/01/2015, 15 h53 - Elis: Ok (-) Abraços!

12/01/2015, 15h59 - Thiago: Pode deixar, abraço!

12/01/2015, 16h00 - João: Você tem algum tema [que] enxerga como prioritário ou mais interessante pra gente, professor?

12/01/2015, 16h00 - João: Tipo aquele de LKC e matrizes ou algum outro?

12/01/2015, 16h47 - Pesquisador: O interessante é que tenha algo para visualizar e manipular..

12/01/2015, 16h47 - Pesquisador: LKC e LKT são mais teóricos

12/01/2015, 16h47 - Pesquisador: Vcs poderiam fazer um stand com teorias e aplicações de Grafos

12/01/2015, 16 h48 - Pesquisador: Aí poderiam falar da aplicação na Física

12/01/2015, 16h48 - Pesquisador: Na robótica (prof. Fernando [nome fictício] estudou isso e pode ajudar vcs)

12/01/2015, 16h48 - Pesquisador: E o jogo sprouts que falei da outra vez 
12/01/2015, 16h52 - Elis: Show de bola. Vai ficar bem criativo *

12/01/2015, 16h53 - Pesquisador: Se quiserem falar de outra coisa também... essas foram algumas idéias que tive

12/01/2015, 17h37 - Sabrina: Blz. Vamos olhar de forma mais detalhada e decidir

A primeira proposta de trabalho, destacada na conversa, refere-se às Leis de Kirchoff das Correntes (LKC) e das Tensões (LKT), abordadas na disciplina de Análise de Circuito de Corrente Contínua, do primeiro ano do curso técnico em automação industrial. Outra ideia surgida foi o Sprouts, um jogo de lápis e papel com propriedades matemáticas, inventado por John Horton Conway e Michael S. Paterson, na Universidade de Cambridge, no início dos anos de 1960. Após discutirem e analisarem as possibilidades, os alunos optaram por uma terceira abordagem: a construção de uma maquete eletrônica que retomasse o Problema das Sete Pontes de Konigsberg, que deu origem à Teoria de Grafos - área da matemática que possui diversas aplicações na área de tecnologia ${ }^{4}$ e que passou a ser considerado conteúdo de ensino médio do estado (ESPÍRITO SANTO, 2008).

O Problema das Sete Pontes de Königsberg foi discutido no século XVIII, quando os cidadãos de Königsberg, ao observarem que a cidade russa era composta por quatro áreas de terra separadas por um rio, fixaram a tarefa de cruzar cada uma das sete pontes apenas uma vez e, sendo possível, retornar ao ponto de partida.

Figura 1 - Esboço da cidade de Königsberg

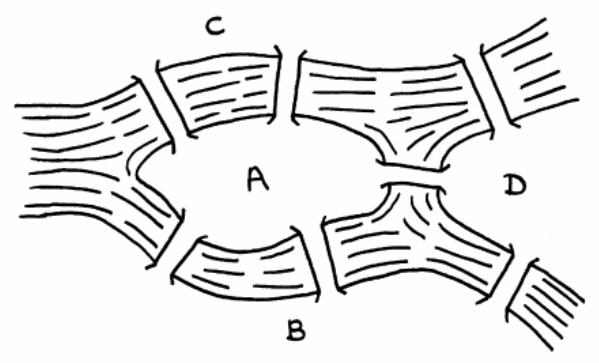

(Fonte: Hopkins \& Wilson, 2004, p. 198)

A partir do Problema das Pontes de Königsberg, Leonard Euler criou um modelo matemático que simulasse a cidade russa, que é o que hoje chamamos de grafo. Ele representou as porções de terra (ilhas e margens) por pontos e as pontes por linhas ligando esses pontos (Figura 2). Apesar de não utilizar as denominações atuais da Teoria dos Grafos, Euler analisou a quantidade de pontes que incidiam em cada ilha e percebeu que só se poderia realizar um caminho passando em todas as pontes uma única vez se, e somente se, cada porção de terra possuísse uma quantidade par de pontes. 


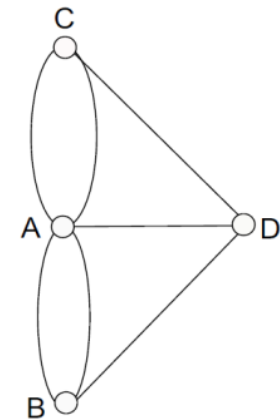

(Fonte: Adaptado de Malta, 2008, p. 12)

Observamos as primeiras aproximações entre ciência e tecnologia no primeiro trimestre de 2015, com definição da maquete eletrônica como tema do trabalho e com a inclusão no grupo de um professor da área técnica do Ifes Linhares, com formação em engenharia elétrica. A inclusão desse novo participante no projeto foi importante, pois motivou os alunos a refletirem sobre os conteúdos já estudados em anos anteriores, de modo a empreendê-los neste projeto. Um trecho a seguir exemplifica essa retomada:

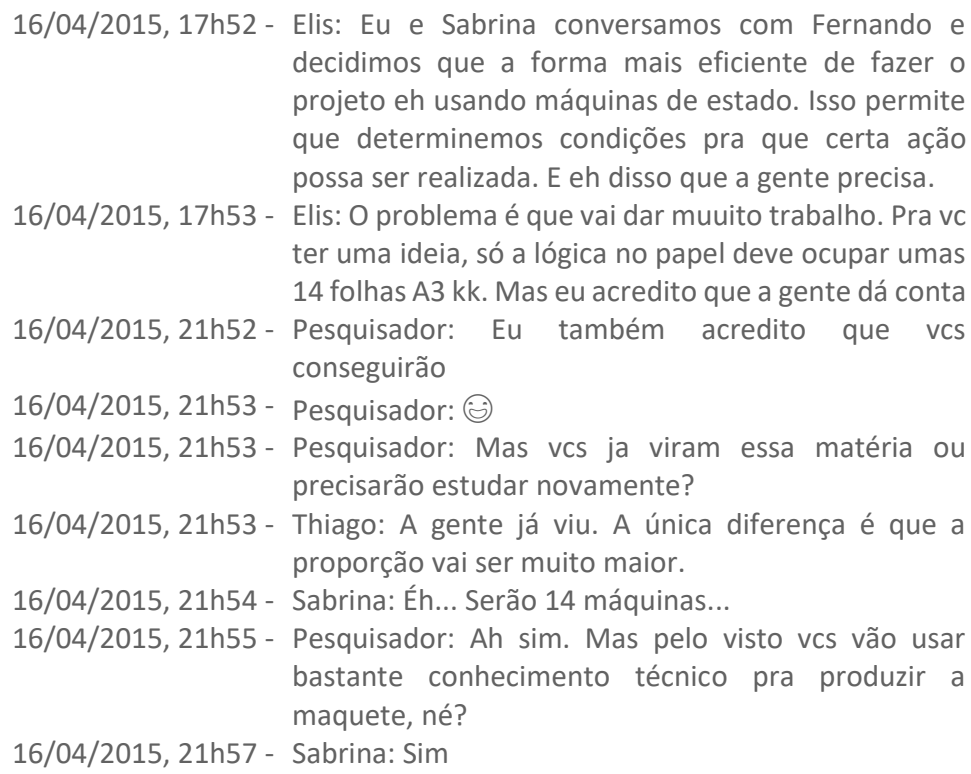

No primeiro projeto da maquete eletrônica, os alunos-pesquisadores planejaram utilizar dispositivos eletrônicos como LEDs (Light Emitting Diode, diodos emissores de luz), botoeiras pulsantes e uma placa de prototipagem eletrônica (Arduíno ${ }^{5}$ ), para que os participantes pudessem interagir ao tentar solucionar o problema. Nessa primeira concepção de maquete, em cada uma das regiões haveria um botão, e em cada ponte, um LED. Assim, quando o participante escolhesse atravessar uma determinada ponte, esse deveria pressionar o botão da região inicial e, em seguida, pressionar o segundo botão, da região de destino. Isso acenderia o LED da ponte que ligasse essas duas regiões, indicando que a ponte foi atravessada. Em seguida, o participante continuaria percorrendo o caminho, na tentativa de resolver o enigma proposto. 
Ao socializar essa proposta em um dos seminários, os alunos-pesquisadores notaram que o projeto necessitaria de acréscimos à programação, o que inviabilizaria a construção da maquete eletrônica até a feira da 4a Semana da Matemática do Ifes, em maio de 2015. Sobre essas reflexões, corroboramos com Pacheco (2011), que destaca que o fazer pedagógico dos institutos rompe com um formato que lida com o conhecimento de forma fragmentada, uma vez que percebem a pesquisa como princípio educativo e científico.

A modificação do projeto diminuiu a complexidade do código de programação da maquete, permitindo que os alunos utilizassem a árvore de possibilidades, ou máquina de estados. Essa foi, para os alunos, uma forma confiável de construir a lógica do programa, ainda que precisassem listar todos os caminhos possíveis para implementá-lo na lógica de programação, como apresentado na Figura 3.

Figura 3 - Sabrina construindo uma máquina de estados finitos

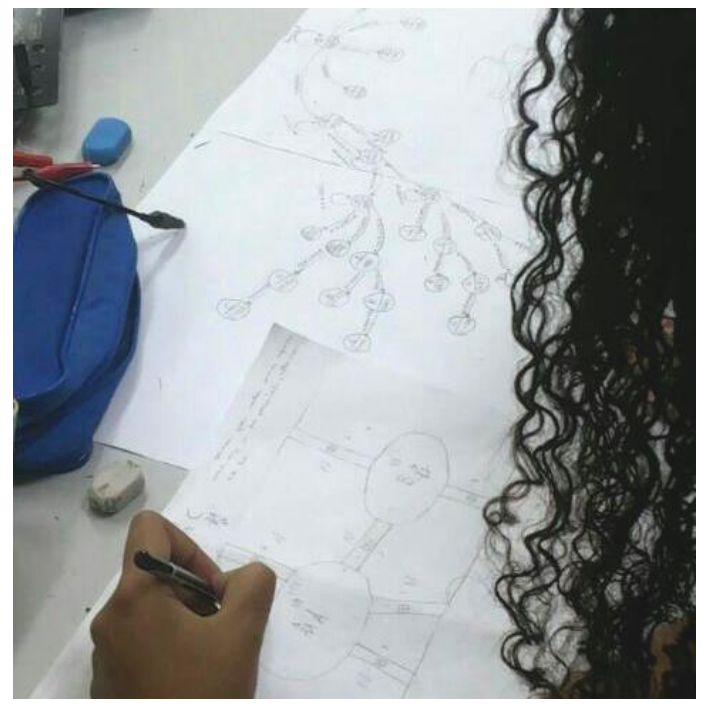

(Fonte: Acervo dos pesquisadores, 2015)

As máquinas de estados finitos são modelos matemáticos usados para representar programas de computadores ou circuitos lógicos. Essas máquinas de estado podem modelar um grande número de problemas, entre os quais a automação de design eletrônico, o projeto de protocolo de comunicação, a análise e outras aplicações de engenharia (OLIVEIRA, 2005). Por exemplo, a seguir temos a máquina de estado referente à ilha central com três pontes de acesso. 
Figura 4 - Máquina de estado referente a uma ilha da maquete eletrônica

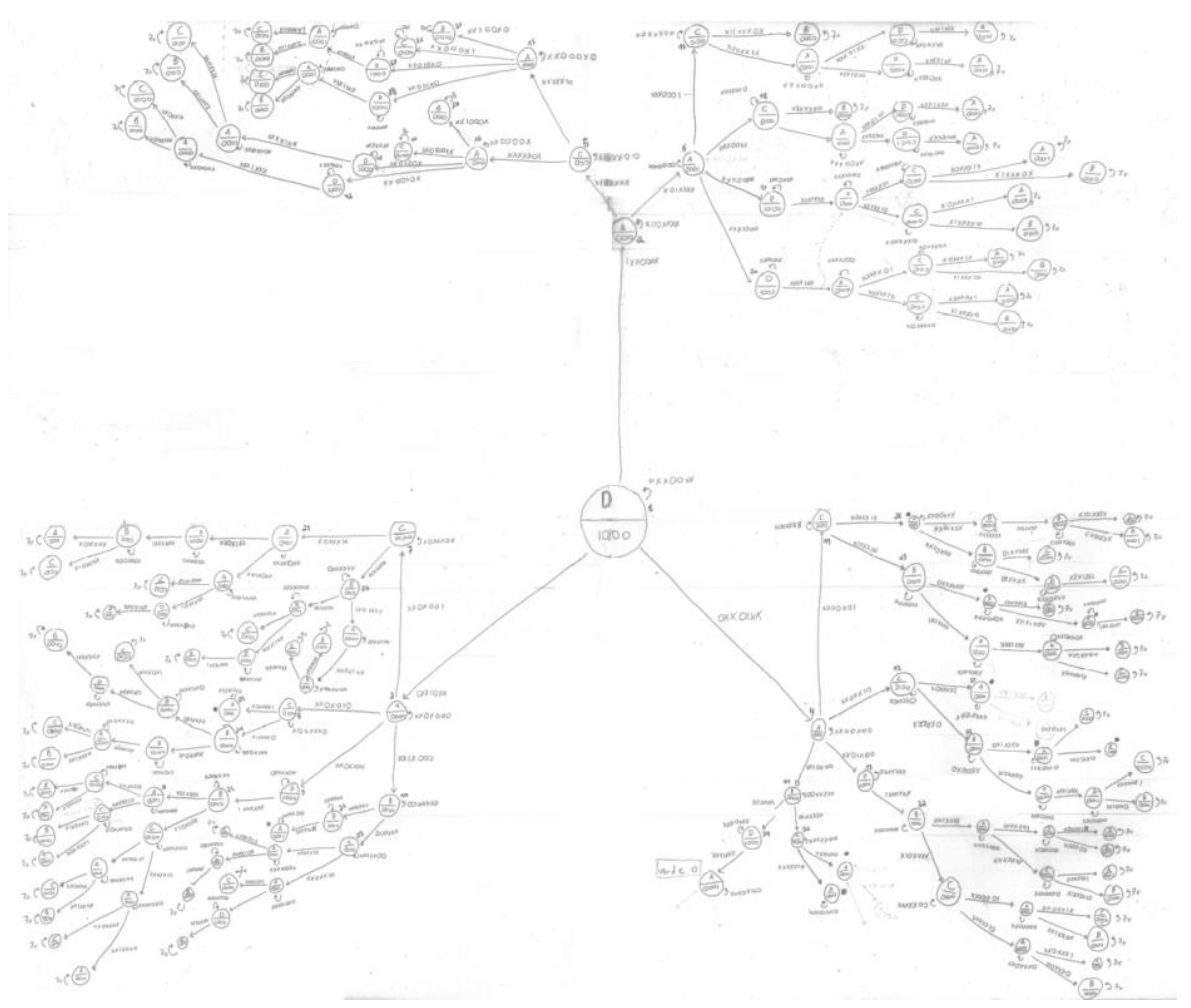

(Fonte: Acervo dos pesquisadores, 2015)

Ao analisar a máquina de estado apresentada anteriormente, percebemos que esta é representada por meio de um grafo direcionado (digrafo). Sobre esse aspecto, Oliveira $(2005$, p. 29) destaca que nessa estrutura "os vértices são os artigos e existe uma aresta do artigo A para o artigo B se, e somente se, A contém um link para B". $O$ autor ainda enfatiza que o desenvolvimento de algoritmos para manipular grafos é um importante tema da ciência da computação, área de origem das máquinas de estado finito. Nesse caso, observamos mais uma interação entre um elemento matemático - o grafo - e sua aplicação direta na área de tecnologia.

Na parte da programação, o método foi escolhido por seguir corretamente a máquina de estados. A linguagem de programação utilizada foi a $C$, única que os alunos conheciam até então; a interface de programação escolhida foi a MPLAB ${ }^{\circledR}$ $\mathrm{X}$ Integrated Development Environment (IDE), disponível no laboratório da escola. $\mathrm{O}$ microcontrolador utilizado inicialmente pertence à família $\mathrm{PIC} 16^{6}$ e possui um médio custo de mercado quando comparado a outros microcontroladores de capacidade similar. Desenvolvemos uma placa de circuito impresso, utilizando o microncontrolador PIC16F877A e uma fonte de 5Vcc (volts em corrente contínua), conectadas a essa placa todas botoerias e todos os LEDs da maquete.

No segundo projeto, foram implementados novos botões e LED em cada localidade, ilha, margem ou ponte, e os botões principais passaram a ficar nas pontes. Veja o esquema a seguir sobre utilização da maquete eletrônica, com um trajeto aleatório: 

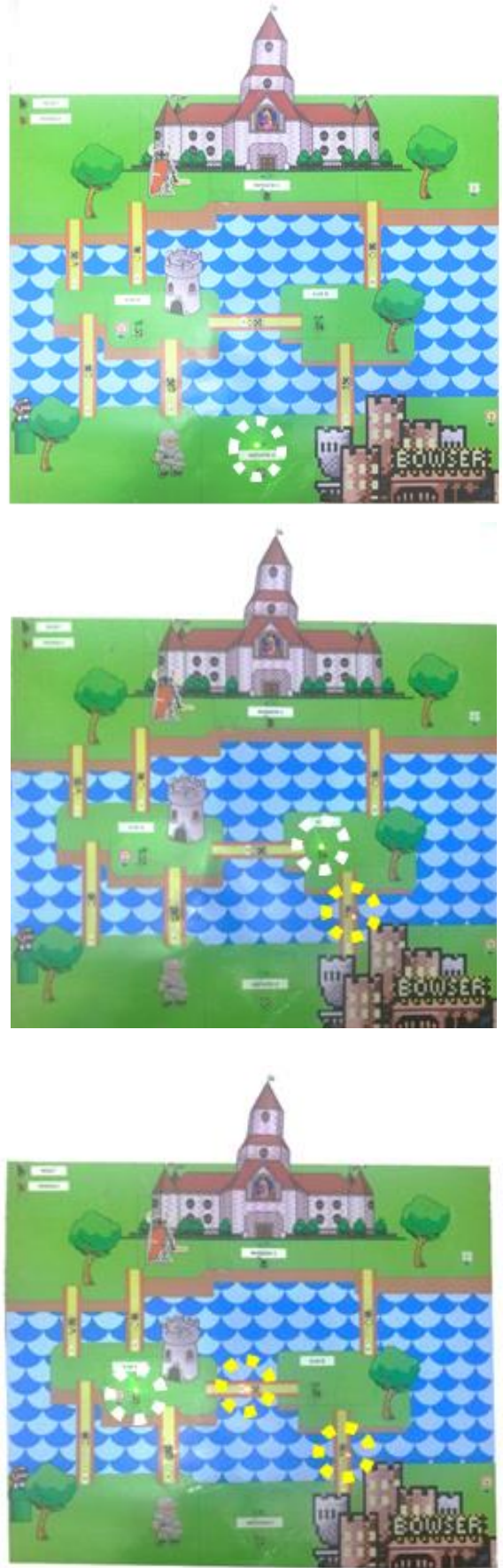

O usuário inicia a interação, selecionando a ilha de partida, o que acende um LED verde. Nesse exemplo, o usuário optou por começar da margem sul.

Em seguida, o usuário pressiona o botão de uma das pontes que dão acesso à região onde ele está, acendendo seu LED amarelo e indicando o novo local onde o usuário está com um LED verde. Se o usuário pressionar o botão de uma ponte que não dá acesso à região onde ele se encontra, nada acontece.

Nesse exemplo, ao sair da margem sul e ir para a ilha com a árvore, apagou-se o LED da margem sul e acenderam-se o da ponte percorrida e o da ilha da árvore.

Suponha que o trajeto continuou, indo da ilha da árvore para a ilha com a torre. Assim, apagou-se o LED da ilha da árvore, acenderam-se os da ponte recématravessada e da ilha da torre e mantevese acesso o LED da ponte percorrida inicialmente. 

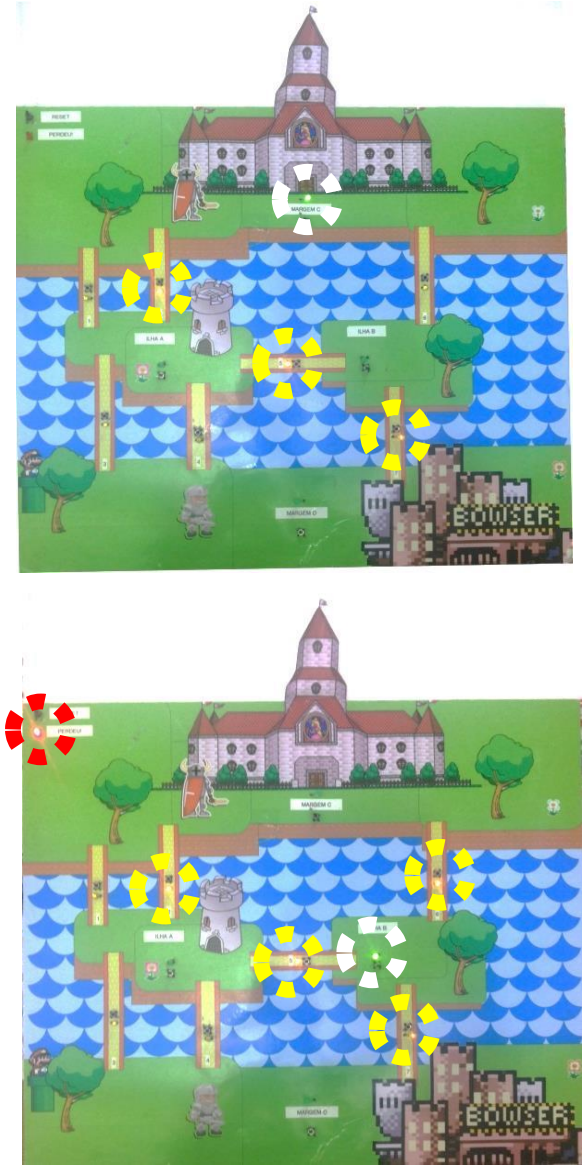

Da ilha da árvore, considere que o usuário optou por ir para a margem norte, pela ponte maior. Dessa forma, apaga-se o LED da ilha da torre, acendem-se os da margem norte e o da ponte recém-atravessada e mantêm-se acessos os LEDs das pontes percorridas nas etapas 2 e 3 .

Se o usuário optar por voltar para a ilha da árvore, apaga-se o LED da margem norte; acendem-se o verde da ilha da árvore e o amarelo da ponte recématravessada; e mantêm-se acessos os três amarelos das pontes utilizadas. Como não há mais possibilidade de deixar a ilha da árvore sem repetir nenhuma ponte, acende-se um LED vermelho no canto superior-esquerdo, indicando fim das possibilidades de percurso. O usuário deve, então, pressionar o botão de reiniciar, que fica ao lado do LED vermelho.

A primeira apresentação da maquete em uma feira aconteceu na 4a Semana da Matemática do Ifes, em maio de 2015. Até o evento, o grupo não havia conseguido unir todos os programas respectivos de cada ilha/margem. Isso ocorreu porque o microcontrolador utilizado não possuía memória suficiente para armazenar todas as linhas de programação. Devido a isso, no dia da apresentação, os alunos compilaram um programa por vez, ou seja, o participante escolhia uma ilha/margem para iniciar seu percurso e aguardava um momento para que o programa fosse compilado no computador. A partir desse momento, ele poderia utilizar a maquete eletrônica. Além desse contratempo, ao chegar ao evento, os alunos-pesquisadores identificaram problemas de funcionamento da maquete, decorrentes do transporte no trecho de Linhares à capital capixaba. Com apoio de professores do curso de Eletrotécnica do campus Vitória, os estudantes conseguiram reparar a maquete a tempo para apresentação. 
Figura 5 - Alunos reparando os problemas na maquete eletrônica

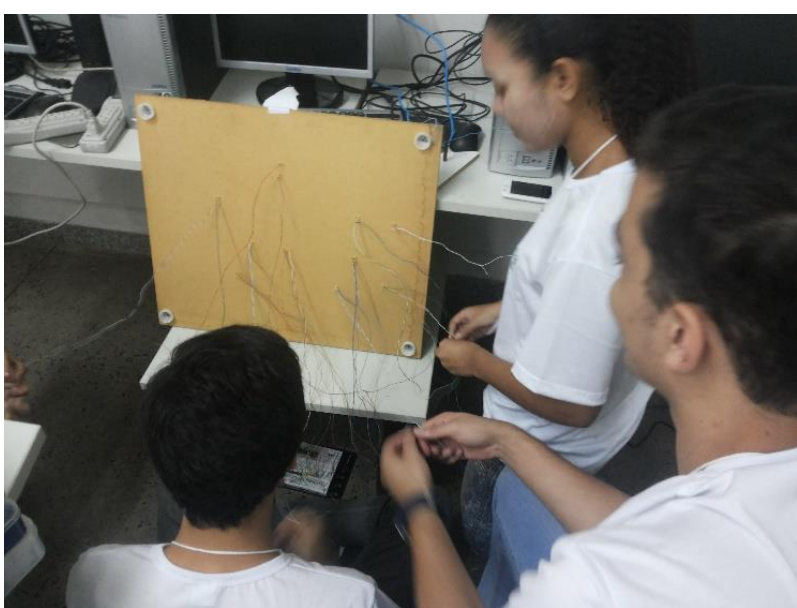

(Fonte: Acervo dos pesquisadores, 2015)

A segunda exibição do protótipo para ensino de grafos aconteceu na IV Feira de Ciência e Engenharia do Espírito Santo (Fecieng - ES). Segundo a organização do evento, essa feira incentiva a criatividade e a inovação em estudantes de educação básica, por meio do desenvolvimento de projetos com fundamento científico, nas diferentes áreas das ciências e engenharia. Na quarta edição da Fecieng - ES, cerca de 200 trabalhos foram inscritos e desenvolvidos por alunos e professores de escolas dos ensinos fundamental, médio e EJA, das redes Municipal, Estadual e Federal. Desses, 60 foram selecionados para apresentação no evento, que aconteceu entre os dias 27 e 29 de outubro de 2015. Para a IV Fecieng - ES, os alunos substituíram o microcontrolador PIC16F877A pelo PIC18F4550, que, dentre outras vantagens, possui uma maior memória de programa que o anterior. Assim, os alunos conseguiram compilar toda a programação em um único microcontrolador, não sendo mais necessário o acompanhamento de um computador.

Além da interação entre elementos matemáticos e suas aplicações na área de tecnologia, durante a realização do projeto para feira de matemática, os alunos retomaram diversos assuntos da área técnica, como exposto no quadro seguinte.

Quadro 2 - Síntese dos conteúdos técnicos utilizados durante o projeto da maquete eletrônica

\begin{tabular}{c|c|c} 
Conteúdo & Disciplina & Ano do curso \\
\hline Circuito de pull-up e pull-down & $\begin{array}{c}\text { Análise de Circuitos de Corrente } \\
\text { Contínua / Instrumentação Básica }\end{array}$ & 10 ano \\
\hline Conhecimentos de programação & Lógica de Programação & 10 ano \\
\hline Circuitos Elétricos & Análise de Circuitos de Corrente & 20 ano \\
\hline Máquinas de estados finitos & Sistemas Digitais I & 30 ano \\
\hline Utilização de microcontroladores da & Sistemas Digitais I e II & 30 e 40 anos
\end{tabular}

Fonte: Elaborado pelos autores, 2015. 
Observamos, no Quadro 2, que os conteúdos técnicos envolvidos na construção da maquete eletrônica foram apresentados aos alunos em todos os quatro anos de curso. Assim, ao retomarmos os conteúdos matemáticos e profissionais explorados, acreditamos ter desenvolvido um trabalho interdisciplinar. A partir da definição de Ramos (2005, p. 116), percebemos como essa abordagem pode favorecer a compreensão dos conceitos pelos alunos:

\footnotetext{
A interdisciplinaridade, como método, é a reconstituição da totalidade pela relação entre os conceitos originados a partir de distintos recortes da realizada; isto é, dos diversos campos da ciência representados em disciplinas. Isso tem como objetivo possibilitar a compreensão dos significados dos conceitos, das razões e dos métodos pelos quais se pode conhecer o real e apropriá-lo em potencial para o ser humano.
}

Em nosso caso, os conceitos científicos de Teoria de Grafos, como "pontos de partida", reverteram-se em conteúdos de ensino, sistematizados em diferentes áreas de conhecimento e em diversas disciplinas: Análise de Circuitos de Corrente Contínua e Alternada, Instrumentação Básica, Lógica de Programação e Sistemas Digitais I e II. A partir do exposto por Ramos (2005), percebemos, então, que "conhecimentos gerais e conhecimentos profissionais se distinguem metodologicamente e em suas finalidades situadas historicamente; porém, epistemologicamente, esses conteúdos formam uma unidade" (RAMOS, 2005, p. 120).

\section{ALGUMAS CONSIDERAÇÕES}

Nessas experiências com a maquete eletrônica na Feira de Matemática do Ifes e na IV Fecieng -ES, concluímos que esse recurso foi compatível para a abordagem da Teoria dos Grafos do ensino médio. Verificamos, em ambas as ocasiões, que a maquete aproximou a matemática dos participantes das feiras, despertando o interesse, e promoveu a formulação de questões, conjecturas, testes e argumentações, etapas de uma investigação matemática (PONTE et al., 2009; SKOVSMOSE, 2000).

Corroboramos, junto aos alunos-pesquisadores da educação profissional, a tese de que conteúdos são conceitos e teorias que constituem sínteses da apropriação histórica da realidade material e social pelo homem. Ademais, verificamos que esses estudantes reconheceram a Teoria de Grafos como conhecimento construído historicamente, a partir do qual se podem construir novos conhecimentos, inclusive técnicos. Nesse caso, acreditamos ter desenvolvido um trabalho interdisciplinar, uma vez que os conteúdos técnicos envolvidos na construção da maquete eletrônica foram apresentados aos alunos em todos os quatro anos de curso e complementados pelo estudo da Teoria de Grafos, em momentos extraclasse.

Ainda sobre a interação ciência e tecnologia, identificamos uma profícua possibilidade estabelecida entre o grafo, elemento matemático e sua utilização para produção da maquete eletrônica, por meio da utilização de máquinas de estados finitos. Dessa forma, apresentamos os projetos de feira de matemática como metodologia para fortalecimento da relação entre ciência e tecnologia na Educação Profissional. 


\title{
Graphs and finite state machines: an interdisciplinary experience with vocational education students
}

\begin{abstract}
We present a master's research clipping that investigated student learning during construction and use of an electronic model for the teaching of Graph Theory. We identified learning from students-researchers in vocational education, in the action-research movement that facilitated the creation of the resource. We started with the questions: how did the science and technology interaction take place in the mathematics fair project? Wich contents were mobilized during the action-research movement? How did this happen? Looking for answers, we analyze Whatsapp conversations and answers to a form and questionnaire, our tools for producing data. In the end, we highlight the relationship between the graph, mathematical element, and its use for the production of the electronic model, through the use of finite state machines. Thus, when we return to the mathematical contents and the professional core, we believe we have developed an interdisciplinary work, reconstituting the totality of knowledge through the relation between different concepts addressed.
\end{abstract}

KEYWORDS: Interdisciplinarity, Mathematics Fair, Vocational Education, Mathematics Education. 
${ }^{1}$ FREIRE, Paulo. Pedagogia da indignação - cartas pedagógicas e outros escritos. São Paulo: Editora Unesp, 2000.

${ }^{2}$ Uma semi realidade é um mundo sem impressões dos sentidos, de modo que somente as quantidades mensuradas são relevantes. Além disso, toda informação quantitativa é exata. A combinação dessas características torna possível sustentar o pressuposto de que há somente uma resposta correta (SKOVSMOSE, 2000).

${ }^{3}$ WhatsApp Messenger é um aplicativo multiplataforma que permite trocar mensagens pela internet. Além das mensagens básicas, os usuários do WhatsApp podem criar grupos, enviar mensagens ilimitadas com imagens, vídeos e áudio.

${ }^{4}$ Dentre as várias aplicações da Teoria de Grafos, podemos citar o sistema de transporte metroviário e o sistema de buscas do Google.

${ }^{5}$ Arduíno é uma plataforma de prototipagem eletrônica de hardware livre e de placa única, com linguagem de programação padrão, essencialmente $\mathrm{C} / \mathrm{C}++$. $\mathrm{O}$ objetivo do projeto Arduíno é criar ferramentas acessíveis, com baixo custo, flexíveis e fáceis de se usar tanto por profissionais quanto por amadores. Pode ser usado para o desenvolvimento de objetos interativos independentes ou ainda para ser conectado a um computador hospedeiro. Uma típica placa Arduíno é composta por um microcontrolador, alguns conectores de entrada e saída digital e analógica, além de uma interface serial e/ou USB, para se interligar ao hospedeiro, que é usado para programá-la em tempo real.

${ }^{6}$ Os PIC - Programmable Interface Controllers (Controladores de Interface Programável, em português) são uma família de microcontroladores que processam dados de 8,16 e 32 bits, possuem alta velocidade de processamento e são populares; também possuem extensa coleção de notas de aplicação, disponibilidade de ferramentas de desenvolvimento de baixo custo (ou gratuitos) e capacidade de programação serial e reprogramação com memória flash.

\section{REFERÊNCIAS}

ESPÍRITO SANTO (Estado). Secretaria da Educação. Currículo Básico Escola Estadual - Ensino médio: área de Ciências da Natureza. Vitória: SEDU, 2009. v. 2. Disponível em:

$<$ http://www.educacao.es.gov.br/download/SEDU_Curriculo_Basico_Escola_Esta dual.pdf>. Acesso em: 06 out. 2012.

FIORENTINI, Dario; LORENZATO, Sérgio. Investigação em Educação Matemática: percursos teóricos e metodológicos. Campinas, SP: Autores Associados, 2009.

HOPKINS, Brian; WILSON, Robin J.. The truth about Konisberg. The College Mathematics Journal, v. 35, n. 03, p. 198-207, mai, 2004.

MacTutor History of Mathematics archive. Gustav Robert Kirchhoff. Disponível em: <http://www-history.mcs.st-and.ac.uk/Biographies/Kirchhoff.html>. Acesso em: 28 fev. 2016. 
MALTA, Gláucia Helena Sarmento. Grafos no Ensino Médio: uma inserção possível. 2008. 158f. Dissertação (Mestrado Profissional em Ensino de Matemática) - Programa de Pós-Graduação em Ensino de Matemática, Universidade Federal do Rio Grande do Sul, Porto Alegre, 2008.

MANFREDI, Silvia Maria. Educação profissional. In: STRECK, Danilo R.; REDIN, Euclides; ZITKOSKI, Jaime José. Dicionário Paulo Freire. 2. ed., ver. amp. 1 reimp. Belo Horizonte: Autêntica Editora, 2010.

MOURA, Dácio Guimarães. Feiras de Ciências: necessidade de novas diretrizes. Revista Presença Pedagógica, n. 6, p. 15-20, nov./dez. Belo Horizonte, 1995.

OLIVEIRA, Luciano José de. A Modelagem Matemática de Máquinas de Estado Finito. Monografia (Bacharelado em Ciência da Computação) - Curso de Ciência da Computação da Faculdade de Jaguariúna, Jaguariúna, 2005.

PACHECO, Eliézer. Institutos Federais: uma revolução na educação profissional e tecnológica. Moderna: Brasília, 2011; São Paulo, 2011.

PONTE, João Pedro da; BROCARDO, Joana; OLIVEIRA, Hélia. Investigações matemáticas na sala de aula. 2. ed. Belo Horizonte: Autêntica, 2009.

RAMOS, Marise. Possibilidades e desafios na organização do currículo integrado. In: FRIGOTTO, Gaudêncio; CIAVATTA, Maria; RAMOS, Marise (orgs). Ensino Médio Integrado: concepção e contradições. São Paulo: Cortez, 2005.

SÁ, Lauro Chagas e. Construção e utilização de maquete eletrônica para ensino de grafos: aprendizagens discentes a partir de uma abordagem históricoinvestigativa. Dissertação (Mestrado Profissional em Educação em Ciências e Matemática) - Instituto Federal do Espírito Santo, Vitória - ES, 2016.

SILVA, Hélio dos Santos; TOMELIN, Luciane Zickuhr. Construção, orientação e avaliação de trabalhos em Feiras de Matemática. Blumenau-SC: Editora e Gráfica Odorizzi, 2008.

SKOVSMOSE, Ole. Cenários para Investigação. Trad. Jonei Cerqueira Barbosa. Bolema, Rio Claro - SP, v. 13, n. 14, 2000, p. 66-91.

THIOLLENT, Michel. Metodologia da pesquisa-ação. 18. ed. São Paulo: Cortez: 2011. 


\section{RBECT}

DOI: 10.3895/rbect.v10n1.5716

Como citar: SÁ, L. C.; SÁ, F. B.; SILVA, S. A. F. Grafos e máquinas de estados finitos: uma experiência interdisciplinar com estudantes da educação profissional. Revista Brasileira de Ensino de Ciência e Tecnologia, v. 10, n. 1, 2017. Disponível em: <https://revistas.utfpr.edu.br/rbect/article/view/5716>. Acesso em: $x x x$.

Direito autoral: Este artigo está licenciado sob os termos da Licença Creative Commons-Atribuição 4.0 Internacional.

\section{(c) (1)}

